\title{
XXIX. Account of experiments made on a mineral called cerite, and on the particular substance which it contains, and which has been considered as a new metal
}

\section{Vauquelin}

To cite this article: M. Vauquelin (1805) XXIX. Account of experiments made on a mineral called cerite, and on the particular substance which it contains, and which has been considered as a new metal, Philosophical Magazine Series 1, 22:87, 193-200, DOI: 10.1080/14786440508562442

To link to this article: http://dx.doi.org/10.1080/14786440508562442

$$
\text { 曲 Published online: } 18 \text { May } 2009 .
$$

Submit your article to this journal ए

\section{山ll Article views: 6}

Q View related articles ¿

Citing articles: 1 View citing articles $[7$ 
XXIX. Account of Experiments made on a Mineral called Cerite, and on the particular Sulstance which it conlains, and which has been considered as a new Metal. By M. VAUQuELIN*.

M. Klaproth wrote to me, about eight months ago, that he had discovered, in a mineral of Batsnaes, in Sweden, a new earth to which he had given the name of ochroit, on account of the red colour which it assumes by calcination. He even sent me in a letter a small specimen of this substance; and having discovered in it, by several trials, the presence of a considerable quantity of oxide of iron, I started some doubts, in a note which 1 read in the Institude, in regard to the colour of that earth. I observed also in the same note, that this substance had as many metallic properties as earthy characters; but that the small quantity of it which I had in my possession did not allow me to give any decisive opinion on this subject $\uparrow$.

Some time after, Messrs. Berzelius and Hisenger, having been informed, by their correspondents at Paris, of M. Klaproth's labour, wrote to me to claim a priority, stating that they had sent to $M$. Klaproth the specimens of that mineral which he had employed for his experiments, and that at the same time they had announced to him that they had found a new metal in it. I can give no opinion on this difference. I shall only observe, that the well known delicacy of M. Klaproth, and the high reputation he has justly acquired by his numetous and important discoveries, render it very improbable that he would appropriate to himself the discovery of another. M. Klaproth must, no doubt, have received from another quarter the mineral in question; and his labour was perhaps terminated before he acquired any information respecting that of the Swedish chemists. What seems to justify this opinion is, that they obtained results entirely different.

Every thing, therefore, seems to show that M. Klaproth of Berlin, and Messrs. Berzelius and Hisenger of Stockholm, made experiments at the same time on the same mineral without having any communication with each other; and that each may have had the honour of the discovery.

The Swedish chemists transmitted to Paris a memoir on

* From Annales du Muśúm National d'Hustoire Naturelle, No. 30.

+ See Annales de Chimie, No. 149, Flareal 30, an 12.

Vol.22. No. 87. August 1805. N 
this subject written in Swedish. M. Limdbon undertook a translation of it, and caused it to be printed in the $A n$, nales de Chimie*. In this memoir they give a hislory of the mineral, and point out the places where it is found, and the substances which accompany it: they then give an account of the methods they employed to ascertain the nature of it: they give the characters of the new substance it contains, and which they consider as a peculiar metal, to which they give the name of cerium; a denomination taken from the planet Ceres, discovered by M. Piazzi : they have thence formed that of cerite, to denote the natural ore of that metal.

About the end of November, that year, I received, by the care of Messrs. Hisenger and Berzelius, specimens of this fossil; with an invitation to repeat their experiments, and to determine whether the substance in question ought to be classed with the earths or the metals. I charged myself the more readily with this labour, as it furnished me with an opportunity of subjecting to experiment a new substance, and of pronouncing in regard to the opinion of respectable philosophers, whose sole object is truth.

It will be seen by this memoir that the force of facts has obliged me to adopt the opinion of the Swedish chemists. I must not omit to mention that I have been seconded in my experiments by Messrs. Tassaert and Bergman, hoth of whom are well versed in practical chemistry.

\section{Physical Properties of Cerite.}

This mineral is of a slight rose colour : it is sufficiently hard to scratch glass: its specific gravity is $45 \cdot 30$, and its dust is grayish : it becomes reddisb by calcination, and loses twelve per cent.

There are some varieties which contain martial pyrites, and which are traversed by veins of green actinote.

\section{Preliminary Trials on Cerite.}

This mineral, when pulverized in a mortar of silex, does not increase in weight, which indicates that its hardness is not very great : its dust is of a rust gray colour.

When exposed to heat in a retort there are obtained some drops of water, which are condensed in the neck of the ressel.

The dust of cerite is powerfully attacked by the nitric muriatic and nitro-muriatic acids; caloric is developed, and

- No. 150, Prairial 30, an 12. 
there is disengaged carbonic acid as well as nitrous gas when nitric acid is employed.

After ebullition of half an hour the action of the acids appears to be exhausted, and there remains at the bottom of the vessel a dust more or less coloured, which is the silex contained in the mineral.

When cerite is treated with eight or ten times its weight of acid it is entirely decomposed by one operation, and without the necessity of beginning a second time; yet it is impossible by these means to obtain silex perfectly pure : it always retains a certain quantity of metallic oxide. It is only by fusing this earth with an alkali, and then combining it with an acid, that it is possible to obtain it pure, and free from all colouring matter : it generally forms about seventeen hundredths of the mineral. When the solutions of this matter are evaporated to dryness and the residuum is dissolved in water, there is formed a slight white precipitate, which appears to be a little silex which the acid held in solution.

Solutions of cerium are of a yellowish red colour, like that of the oxide of iron at its maximum of. oxygenation; but when cerium is little oxidated they are only of a rose colour, similar to those of manganese and cobalt.

These solutione, decomposed by ammonia, furnish a very voluminous precipitate, which has the appearance of alumine mixed with oxide of iron, but which greatly differs from it in its properties : when dried in a gentle heat this precipitate is redueed to a granulated powder of a pale yellow colour, which becomes of a brick red by calcination. The matter simply dried in the air redissolves readily in the nitric and muriatic acids; but the red oxide, that which has not been calcined, is scarcely attacked, and does not dissolve in muriatic acid without producing a very considerable quantity of oxygenated muriatic acid.

The nitric solution readily crystallizes : the salt which it furnishes is soluble in alcohol: in regard to the muriatic Bolution it is very difficult to obtain crystals : this salt when dried is deliquescent.

The nitric and muriatic solutions are decomposed by alkaline sulphates, phosphates, borates, oxalates, tartrites, and carbonates : with sulphates there are formed yellow precipitates too soluble in water to be subjected to analytical experiments : besides, a part of the iron oxidated to a maximum is precipitated at the same time. The precipitate formed by the borates is still more suiuble in acids : that produced by oxalates is attended with the inconvenience of 
carrying with it a little iron, which gives it a slight tint of a rose colour : it is soluble in acids. The tartrites form a precipitate much less soluble, which does not contain iron; but it is entirely soluble in caustic alkalies as well as in an excess of its concentrated acid, from which it is afterwards separated by water. Phosphates occasion a precipitate which is not soluble in acids without the aid of heat: iron remains in intimate combination with it. Prussiates precipitate solutions of cerium white, even when they contain evident traces of iron. All the precipitates here spoken of are white, and retain that colour after desiccation, except the phosphate, which becomes grayish. Sulphurets and hydro-sulphurets precipitate solutions of cerium white: the precipitates when washed retain their white colour in drying, and dissolve in acids with effervescence : carbonic acid is disengaged, but not an atom of hydrogenated sulphuret; which proves that cerium does not unite with sulphurized hydrogen.

Zine, tin, and iron, immersed in a solution of muriate of cerium, do not effect a reduction of it. They precipitate a black matter, which is in too small quantity to be analysed : there is deposited at the same time a white powder, which appears to be an oxide of the precipitating metal.

An alcoholic solution of gall-nuts produces in muriate of cerium a yellowish precipitate not very abundant. The addition of a few drops of ammionia determines a very voluminous one of a brown colour, which becomes black and brilliant by desiccation : by the action of heat it resumes a beautiful brick red colour.

-When the silex extracted from cerite is fused with an alkali, it is observed that the mixture assumes a beautiful pale straw colour, which soon passes to brown: if the surfaces be often renewed the whole matter becomes brown, but by adding a little charcoal this colour vanishes entirely.

Having made these preliminary trials on cerite, and ascertained the principal properties of the particular substance which it contains, I undertook to analyse it, in regard to quantity, in the following manner :

A hundred parts of this mineral in fine powder were mixed with ten times their weight of nitro-muriatic acid, and subjected to ebullition for an hour: the mixture being diluted with water, and filtered, left on the filter a brown Just, which was dried, and fused with caustic potash. The mixture being diluted with water, anci then dissolved in muriatic acid, evaporated to dryness, and redissolved in water, left a powder which when collected on a filter, washed, 
washed, and calcined, weighed seventeen parts: it was silex, still slightly coloured yellow.

The nitro-muriatic solution being evaporated to dryness, and its residuum redissolved in water, left about one part of silex coloured by a little oxide of cerium.

The same solution freed from silex, and united to the washings of the silex, was decomposed by ammonia: the oxide of cerium and the oxide of iron precipitated by these means, were separated from the liquor by filtration. The oxalic acid added to this liquor formed a precipitate which by calcination gave two parts of lime.

The metallic oxides, united and calcined, weighed serenty parts : they harl a beautiful reduish brown colour. To separate the iron of the cerium the whole was dissolved in muriatic acid : the solution being concentrated to evaporate the excess of acid, then diluted with water and decomposed by tartrite of potash, there was formed a very abundant white precipitate, which being washed till it contained no more foreign salts, then dried, and calcined, gave sixtyseven parts of oxide of cerium.

The water from the washing of the tartrite of the cerium, being united and mixed with hydro-sulphuret of potast; gave a precipitate which became black in the air. It was oxide of iron, the weight of which after calcination was two parts.

Thus 100 parts of cerite subjected to analysis furnished,

\begin{tabular}{lrr} 
1st, Silex - & - & 17 \\
2d, Lime - & - & 2 \\
3d, Oxide of iron & - & 2 \\
4th, Oxide of cerium & - & 67 \\
5th, Water and carbonic acid & 12 \\
\hline & & 100
\end{tabular}

Though the specific gravity of cerite, the varied colours assumed by the particular matter it contains, and the oxygen disengaged during its solution in muriatic acid, afforded great probabilities in regard to the metallic nature of this substance; yet, as it was possible that these properties and these phanomena might be owing to the presence of some known metal, to manganese for example, I endeavoured to discover it by all the means which appeared to me proper for accomplishing that end; hut I did not find any sensible traces of it. It therefore appcars to me altogether improbable that manganese shbuld contribute any thing towards the properties exhibited by the matter of cerite. The case 
is not the same with iron. I must confess that when any traces of it remain in the cerium it communicates to it a darker red colour; but as this matter, when disengaged from iron, as far as chemical means will allow, assumes still a reddish colour by calcination, and as in this state it furnishes as much oxygenated muriatic acid as before, it is equally impossible to ascribe these phænomena to the iron, which, as is well known, produces no oxygenated muriatic acid.

Thus as cerium, in which the slightest sign of the presence of iron, or of any other foreign matter, could not be detected by any means whatever, always assumes a red colour by calcination, and then gives oxygenated muriatic acid during its solution, I am forced to consider it as a metallic oxide rather than an earth, as $M$. Klaproth has done. Hitherto, indeed, chemists were not acquainted with any earth weighing five times as much as water, which has a colour of its own, which absorbs oxygen, and which, dissolving in common muriatic acid, produces oxygenated muriatic acid.

I had great hope that the reduction of this matter to the metallic state by the action of a strong heat would confirm the above probabilities, and convert them into certain truths; but this operation was not attended with all the surcess $I$ expected.

In the first attempt, in which I had put into a charcoal crucible oxalate of cerium reduced to a paste with oil, the whole was volatilized by the violence and duration of the heat : at the bottom of the crucible I found only a metallic grain scarcely so large as the head of a pin, and which was an alloy of iron and cerium. This experiment, if it furnished no metal, proves at least that oxide of cerium is volatile; and I do not know that an earthy substance was ever thus volatilized.

In the second operation I put into a luted porcelain retort a paste made with tartrite of cerium, a little lamp-black and oil, in order that I might collect the metal if it should be volatilized as before; but as the form of my apparatus did not permit me to give as much heat, the matter was not reduced : it remained in its natural state mixed with the charcoal.

There were seen, however, on the sides of the retort a great number of small globules which bad metallic brilliancy, and the substance of which had been manifestly volatilized. Some of the largest of these globules having been detached and broken, exhibited in the inside a white 
colour and a foliaceous texture. There was also in the neck of the retort a slight reddish covering, the taste of which was exceedingly acrid and metallic: the quantity of the matter which formed this covering was too small to be subjected to experiments capable of determining its nature.

Three of these small metallic globules, which weighed together scarcely a fourth part of a grain, being put successively into nitric and muriatic acid, were not sensibly attacked : to effect the solution of them the union of these two acids was necessary. The solution being evaporated, and its residuum dissolved in water, had no colour; its taste was sensibly saccharine; and by the oxalate' of ammonia and the prussiate of potash it gave white and flaky precipitates. It appears, then, that these globules, which $I$ suspected to be iron, are really cerium. What is certain is, that these globules are much more fragile, whiter, and less liable to be attacked by acids than cast iron.

These experiments prove that cerium is volatile at a high temperature, and that it is probably only at the moment of its volatilization that it is reduced, unless we suppose that it is rather volatilized in the state of oxide. This I propose to ascertain by new trials.

Recapitulating what has been said in the course of this notice, it is seen, 1st, That cerium, freed from the foreign matters which accompany it in the mineral, is a substance susceptible of uniting with two quantities of oxygen very distinct.

2d, That with the first quantity it forms a white substance, soluble in acids, without any disengagement of oxygen.

$3 d$, That with the second portion it assumes a slight red colour, combines only with difficulty with acids, and constantly produces a considerable quantity of oxygenated muriatic acid by dissolving in common muriatic acid.

4th, That these oxides do not dissolve in alkalies; but that when boiled together they no longer become coloured by the contact of the air; and that those which are red become white by a slight heat, without, however, combining with the alkalis.

5th, That their combinations with the sulphuric, phosphoric, oxalic, tartareous, and prussic acids are white, and insoluble in water.

6 th, That, on the other hand, those which they form with nitric, muriatic, and acetic acids are very soluble in water and in alcohol, and are even deliquescent. 
7 th, That all these salts have an astringent and highly saccharine taste.

sth, That a good process for separating the iron of cerium is, to precipitate the latter from its nitric or muriatic solution by oxalate of ammonia or tartrite of potash, putting into the liquor a slight excess of acid; or, what is better, is, to calcine the muriate of cerium, to redissolve its residuum in the muriatic acid, to calcine again, and to repeat this three times, in order to sublime entirely the muriate of iron; which succeeds very well.

9th, That cerium does not unite with sulphurated hydrogen, like the other metallic oxides.

joth, That it appears irreducible by those means which generally succeed with the most refractory oxides, but that it is volatile, and that it is probably at this moment that its reduction is effectcd.

11 th, That if, contrary to every appearance, cerium is not a metal, it has, at any rate, much more analogy and relation with that class of bodies than with any other; and for these reasons we shall place it, with Messrs. Hisenger and Berzelius, in that class, till it has been proved that it is better fitted to any other kind of matters.

12 th, In the last place, that by some lucky chance, or means better combined than those hitherto employed, we shall obtain it in the metallic state; and $l$ do not despair myself of meeting with this success.

XXX. Memoir on some zoological Facts applicalle to the Theory of the Earth. Read in the Physical and Mathematical Class of the French National Institute on the $22 d$ of Octoler 1804. By M. PEron, Naturatist to the Expedition for making Discoveries in Australasia.

[Concluded from p. 166.]

I

Irvin

HAVE now terminated the general history of petrified and Hing zoophytes: we have seen them cantoned, as we say, in that zone of the globe comprehended between the 34th degree of north and south latitude, where they fill the sea with dangerous reefs, form new islands, enlarge the old ones, and every where increase the domain of the land at the expense of the ocean which nourishes them in its bosom : we have seen their antient labours rising over the surface of the waves, and appearing again at great heights above their present level. The last phanomenon deserves our at- 